\title{
Fontes de resistência à murcha bacteriana em germoplasma de Capsicum spp. do estado do Amazonas
}

\author{
Liane Cristine Rebouças DEMOSTHENES¹, Jânia Lília da Silva BENTES²
}

\begin{abstract}
RESUMO
A murcha bacteriana, causada por Ralstonia solanacearum, é uma das doenças mais importantes do gênero Capsicum no Brasil. No Amazonas, as condiçóes de elevada temperatura e umidade favorecem o desenvolvimento da doença. O objetivo deste trabalho foi avaliar a resistência à murcha bacteriana de germoplasma, selvagem e comercial, de Capsicum spp. Foram avaliados 22 acessos de Capsicum em casa de vegetação. A inoculação foi feita mediante ferimento das raízes, seguido de adição no solo, ao redor das plantas, de suspensão bacteriana na concentraçáo de $10^{8}$ ufc $\mathrm{mL}^{-1}$. A avaliaçáo foi feita diariamente a partir do quarto dia após a inoculação, em função desenvolvimento dos sintomas. A partir das médias de progresso dos sintomas foi construída a área abaixo da curva de progresso da doença (AACPD), e os dados submetidos ao teste de Scott-Knott ao nível de 5\% de probabilidade, utilizando o programa estatístico SAEG 9.1. Foram selecionados os acessos 30, 20 e 17, da espécie C. chinense, como resistentes à murcha bacteriana para ensaios futuros em programas de melhoramento genético.
\end{abstract}

PALAVRAS-CHAVE: pimentão, pimentas, Ralstonia solanacearum

\section{Sources of resistance against bacterial wilt in Capsicum spp. germoplasm of the Amazonas state}

\section{ABSTRACT}

The bacterial wilt caused by Ralstonia solanacearum is one of the most important in the genus Capsicum in Brazil. In the state of Amazonas,-high temperatures and humidity favor the development of the disease. The objective of this work was to evaluate resistance in germoplasm of wild and commercial Capsicum spp. to bacterial wilt. Twenty two accesses of Capsicum spp. were evaluated in greenhouse conditions. The inoculation was made by means of wounds in the roots, followed by addition of bacterial suspension in the concentration of $10^{8} \mathrm{ufc} \mathrm{ml}^{-1}$ in the soil, around the plants. Plant evaluation was made daily after the fourth day of the inoculation (DAI) considering the symptoms progress. From the average progress of symptoms was constructed the area under the disease progress curve (AUDPC), and the data submitted to the Scott-Knott test at 5\% of probability, using SAEG statistical program. From the average severity notes, we constructed the area under the disease progress curve (AUDPC). The accesses 30, 20 and 17 were selected from $C$. chinense as resistant to the bacterial wilt, for future use in genetic breeding programs.

KEY WORDS: peppers, sweet pepper, Ralstonia solanacearum.

1 Universidade Federal do Amazonas - UFAM. liacristine@ufam.edu.br

${ }^{2}$ Universidade Federal do Amazonas - UFAM. jlbentes@ufam.edu.br 
A murcha bacteriana, causada pela bactéria Ralstonia solanacearum Smith (1896) (Yabuuchi) et al. 1996, é favorecida por condiçóes de umidade e temperatura elevadas e chega a inviabilizar o cultivo de diversas espécies em regióes de clima tropical ou subtropical, bem como na época do verão em regiôes de clima temperado (Hayward 1991). No estado do Amazonas tem se observado a manifestaçáo de murcha bacteriana principalmente nos municípios de Iranduba e Manacapuru, em várias espécies de plantas, dentre elas o pimentão, restringindo a produção de hortaliças no Estado (Coelho Netto et al. 2004).

Este trabalho teve como objetivo identificar fontes de resistência à murcha bacteriana em uma coleçáo de acessos nativos e comerciais de Capsicum spp..

Os ensaios foram conduzidos em casa de vegetação, no setor de produçáo da Faculdade de Ciências Agrárias e no Laboratório de Microbiologia da Universidade Federal do Amazonas, em Manaus. Foram avaliados 22 acessos de $C$. chinense Jack. $e$ C. annuum L., sendo 19 nativos e três cultivares comerciais de pimentão, a saber, Nathalie (Syngenta Seeds Ltda.), Magaly R (Sakata Seed Sudamerica) e Casca Dura Ikeda (Hortec Tecnologia de Sementes). Para a produção das mudas, sementes dos 22 acessos foram semeadas em bandejas de poliestireno expandido de 128 células contendo substrato comercial HT Plantmax (Eucatex, São Paulo). Utilizaram-se duas épocas de semeadura, com intervalo de 15 dias cada uma. Aos 20 dias após a germinação, mudas do primeiro lote foram transplantadas para recipientes de polietileno com capacidade de $500 \mathrm{~mL}$ e as do segundo lote foram transplantadas para recipientes de $250 \mathrm{~mL}$. Para ambos os recipientes utilizou-se mistura autoclavada,de terra e esterco bovino na proporçâo de $3: 1$.

As plantas foram inoculadas uma única vez em duas idades, aos 30 e aos 45 dias após a semeadura. O isolado de $R$. solanacearum foi obtido a partir de plantas com sintoma típico de murcha bacteriana em cultivo de pimentão, situado no município de Iranduba, AM. O isolamento foi feito em meio de cultura LPGA (Kpêmoua et al. 1996) repicando-se, em seguida, para meio de cultura Kelman (Kelman 1954). O isolado foi mantido em água destilada em tubo de ensaio em temperatura ambiente $\left(20^{\circ} \mathrm{C}\right)$ segundo método de Romeiro (2001).

Para a confirmação da identidade do isolado, foram realizados os seguintes testes bioquímicos: teste de Gram por solubilidade em hidróxido de potássio a 3\%, de acordo com Sands et al. (1990), utilizaçáo de asparagina, pigmentação fluorescente em meio B de King, produçáo de inclusões de poli- $\beta$-hidroxibutirato (Bringel 2002). A determinação da biovar foi feita por meio de testes de produção de ácidos a partir de fontes de carbono segundo método de Hayward (1964). Para a inoculação, foi utilizado o isolado P21, biovar
1, cultivado em meio LPGA, durante 48 horas em estufa a $27^{\circ} \mathrm{C}$. Preparou-se a suspensão de inóculo ajustada para a concentração de $10^{8} \mathrm{ufc} \mathrm{mL}^{-1}$ utilizando a escala de McFarland (Király et al. 1974). A inoculação foi feita pela adição de $5 \mathrm{~mL}$ da suspensão de inóculo no solo, ao redor do colo da planta, cujas raízes foram previamente feridas pela introdução de um bisturi no sistema radicular.

A avaliação da reação de resistência à murcha bacteriana foi visual e feita diariamente a partir do quarto dia após a inoculaçáo, durante 23 dias. Avaliou-se o desenvolvimento dos sintomas de acordo com Lopes e Boiteux (2004), por meio de escala de notas variando de 0 a 5 , em que: 0 = ausência de sintomas; 1 = uma folha parcialmente murcha; 2 = duas ou três folhas murchas; $3=$ todas as folhas murchas exceto as do ápice; 4 = murcha da planta inteira; e 5 = planta morta (Winstead e Kelman 1952). A partir das médias de progresso dos sintomas foi construída a área abaixo da curva de progresso da doença (AACPD) segundo Campbell e Madden (1990). O delineamento experimental foi inteiramente casualizado, com 22 tratamentos (acessos) e cinco repetiçóes. Cada repetição foi composta de três plantas inoculadas e duas testemunhas tratadas com água destilada esterilizada. Os dados da AACPD foram analisados por meio do teste de Scott-Knott ao nível de 5\%, utilizando o programa estatístico SAEG 9.0 (SAEG 2007).

Em relação ao progresso dos sintomas da murcha bacteriana para as plantas inoculadas com 30 dias de idade, os acessos 20, 30, 17 e MG foram considerados resistentes apresentando menores valores da área abaixo da curva de progresso da doença (AACPD) (Tabela 1). Os acessos 13, CD, SG 05, BC 16, BC 12 e BC 19 mostraram-se altamente suscetíveis, apresentando valores elevados de AACPD, confirmando sua maior suscetibilidade à doença em relação aos demais.

Os acessos 17, 20 e 30 foram os que apresentaram melhor desempenho nas condiçóes avaliadas para ambas as idades de inoculação das plantas. Em plantas inoculadas com 45 dias de idade, a manifestaçáo da resistência foi mais evidente. $\mathrm{O}$ acesso 17 , cujas plantas se mostraram resistentes quando inoculadas aos 30 dias de idade, apresentou menor valor de AACPD que aquele observado quando inoculado aos 30 dias de idade, podendo ser classificado como altamente resistente. Os dados referentes à AACPD (Tabela 1) também confirmaram a maior resistência desse acesso em relação aos demais. A reaçáo mais suscetível dos acessos ao patógeno, em decorrência da inoculação aos 30 dias de idade pode ser devida ao tecido tenro, facilitando a infecção pela bactéria. Outra razão para o resultado é que, com essa idade, a planta pode não ser capaz de ativar seus mecanismos de defesa em tempo de conter a açáo do patógeno, fator que ainda precisa ser melhor estudado. Os acessos 20 e 30 também se revelaram 
como boas fontes de resistência apresentando menores valores de AACPD. Os acessos BC 16, 13 (C. chinense) e CD (C. annuum) apresentaram maiores médias de notas e valores de AACPD, sendo considerados altamente suscetíveis ao isolado utilizado (Tabela 1). Observa-se que a resistência não está relacionada às espécies de Capsicum testadas, pois acessos de C. chinense se comportaram tanto como resistentes (AC 17, 20 e 30) quanto suscetíveis (BC 16 e 13) à bactéria. Portanto, a resistência pode estar relacionada a alguma característica de resistência intrínseca aos acessos, considerando a grande variabilidade existente tanto em $C$. chinense quanto em $C$. annuum. Alguns estudos realizados em Capsicum, visando obter fontes de resistência às doenças, mostraram resultados semelhantes quanto à variaçáo da reação de resistência dos acessos avaliados. Bento et al. (2009) avaliaram 127 acessos de Capsicum quanto à resistência ao mosaico amarelo do pimentão, causada pelo vírus PePYMV (Pepper yellow mosaic viirus), e encontraram nove acessos resistentes sendo dois acessos da espécie Capsicum baccatum e sete da espécie Capsicum chinense. Cezar et al. (2008) ao avaliarem 86 genótipos de pimentóes e pimentas quanto à resistência a tobamovirus, utilizando duas espécies conhecidas, ToMV (tomato mosaic virus) e PMMoV (Pepper mild mottle mosaic virus), encontraram oito fontes de resistência ao ToMV e, somente, um acesso mostrou-se resistente ao PMMoV.

Outros estudos em Capsicum buscando fontes de resistência à murcha bacteriana também detectaram a variabilidade dentro deste gênero. Lopes e Boiteux (2004) avaliaram 23 acessos de Capsicum considerados resistentes à murcha bacteriana, utilizando isolados das biovares 1 e 3; os autores observaram diferenças entre os acessos na manifestação dos sintomas à inoculação com ambas as biovares, sendo que plantas inoculadas com estirpes da biovar 1 mostraram-se assintomáticas. Uma linhagem de $C$. chinense e uma de $C$. baccatum apresentaram resistência a isolados da biovar 1 , mas foram suscetíveis a dois isolados da biovar 3. Um isolado da biovar 3 mostrou-se o mais agressivo, resultando em índices de doença que atingiram valor igual a 100 .

A resposta à infecçáo por $R$. solanacearum nos acessos estudados deve, ainda, ser melhor investigada para o esclarecimento da natureza do mecanismo de resistência, se estrutural ou bioquímico e qual seu papel na proteção da planta ao patógeno. Rahman et al. (1999) detectaram, na cultivar resistente Kulai, de C. annuиm, a formaçâo de um revestimento nas paredes celulares. Esse mecanismo de resistência confinou a bactéria no interior das células e protegeu a parede celular da degradação enzimática, diminuindo a intensidade da doença. A resposta à infecçáo por $R$. solanacearum nos acessos mais resistentes, deve, ainda, ser melhor investigada para o esclarecimento da natureza do mecanismo de resistência, se estrutural ou bioquímico, a exemplo de Egea et al. (1996)
Tabela 1 - Área abaixo da curva de progresso da doença (AACPD) da murcha bacteriana em plantas de Capsicum spp. Avaliadas com 30 e 45 dias de idade inoculadas com um isolado da biovar 1 de Ralstonia solanacearum em casa de vegetaçãoapós os 23 dias de avaliação.

\begin{tabular}{|c|c|c|c|}
\hline \multicolumn{2}{|c|}{ Plantas com 30 dias } & \multicolumn{2}{|c|}{ Plantas com 45 dias } \\
\hline Acesso & AACPD & Acesso & AACPD \\
\hline $\mathrm{AC} 13$ & 1948,0 a & $A C C D$ & $1401,6 \mathrm{a}$ \\
\hline BC 06 & $1882,4 \mathrm{a}$ & AC 13 & $1366,4 \mathrm{a}$ \\
\hline$A C C D$ & 1880,7 a & BC 16 & $1364,4 \mathrm{a}$ \\
\hline SG 05 & $1774,4 \mathrm{a}$ & SG 05 & $1236,8 \mathrm{a}$ \\
\hline BC 16 & $1751,2 \mathrm{a}$ & AC 16 & $1235,2 \mathrm{a}$ \\
\hline BC 12 & $1689,6 \mathrm{a}$ & SG 04 & $1211,2 \mathrm{a}$ \\
\hline BC 19 & $1688,0 \mathrm{a}$ & BC 12 & $1148,0 \mathrm{a}$ \\
\hline SG 01 & $1595,2 \mathrm{a}$ & SG 01 & $1126,3 \mathrm{a}$ \\
\hline SG 04 & $1592,8 \mathrm{a}$ & BC 19 & $1120,0 \mathrm{a}$ \\
\hline BC 01 & $1573,6 \mathrm{a}$ & $\mathrm{AC} 04$ & $1105,6 \mathrm{a}$ \\
\hline AC 16 & $1572,8 \mathrm{a}$ & BC 01 & $1042,4 \mathrm{a}$ \\
\hline $\mathrm{AC} 04$ & $1560,0 \mathrm{a}$ & AC 01 & $920,8 \mathrm{a}$ \\
\hline $\mathrm{AC} 03$ & $1449,6 \mathrm{a}$ & AC 19 & $785,6 b$ \\
\hline AC 19 & 1386,4 a & BC 06 & $752,8 \mathrm{~b}$ \\
\hline AC 01 & $1383,2 \mathrm{a}$ & AC 03 & 749,5 b \\
\hline AC 02 & 1241,6 b & AC 02 & 725,6 b \\
\hline AC 08 & 1154,3 b & $M G$ & $636,0 \mathrm{~b}$ \\
\hline$M G$ & 1018,3 b & AC 08 & $624,8 \mathrm{~b}$ \\
\hline NT & 964,8 b & NT & 594,3 b \\
\hline AC 30 & 898,4 b & AC 30 & $441,6 \mathrm{c}$ \\
\hline AC 20 & 852,8 b & AC 17 & $433,6 \mathrm{c}$ \\
\hline AC 17 & 732,8 b & AC 20 & $261,6 \mathrm{c}$ \\
\hline
\end{tabular}

Acessos Comerciais: AC CD - Casca dura Ikeda (Hortec), AC MG - Cultivar Magaly R(Sakata), AC NT - Cultivar Nathalie(Syngenta). Os demais constituem os acessos selvagens de Capsicum spp. Escala de notas segundo Wisntead e Kelman (1952). Médias seguidas das mesmas letras não diferem entre si pelo Teste de Scott Knott a $5 \%$ de probabilidade. Plantas inoculadas após 30 e 45 dias de semeadura respectivamente.

que avaliando a resposta da cultivar resistente Smith-5, de $C$. annuum, à infecção por Phytophthora capsici, encontraram altos níveis de capsidiol, uma fitoalexina produzida em solanáceas. Nakaho et al. (2004) detectaram, por meio de microscopia eletrônica de transmissão, que a colonização dos tecidos difere entre cultivares e que nas cultivares resistentes, a presença de um material altamente denso e aposiçôes próximas às células do parênquima limitou o movimento ascendente de $R$. solanacearum nos vasos.

A baixa frequência de fontes de resistência à murcha bacteriana ocorre devido à complexidade e variabilidade do patógeno. A essas características aliam-se à influência das 
condiçóes ambientais, de elevada temperatura e umidade, as quais dificultam a busca de plantas com respostas promissoras para resistência à doença. Considerando que houve maior suscetibilidade das plantas aos 30 dias de idade, sugere-se esse procedimento para a avaliação de resistência à murcha bacteriana em Capsicum visando obter resultados com mais rapidez.

Existe variabilidade genética entre os acessos nativos de Capsicum quanto à resistência à murcha bacteriana. Entre os acessos avaliados, AC 17, AC 20 e AC 30 da espécie $C$. chinense podem ser considerados resistentes à murcha bacteriana causada por $R$. solanacearum biovar 1 .

\section{BIBLIOGRAFIA CITADA}

Bento, C.S.; Rodrigues, R.; Zerbini Junior, F.; Sudré, C.P. 2009. Source of resistance against Pepper yellow mosaic virus in chilli pepper. Horticultura brasileira, 27:196-201.

Bringel, J.M.M. 2002. Biochemical, pathogenic and molecular characterization of Ralstonia solanacearum Biovar 2 isolates of potato and eggplant. Tese de Doutorado, Escola Superior de Agricultura Luiz de Queiroz, Piracicaba, SP. 103 pp. (in Portuguese, with abstract in English).

Campbell, C.L.; Madden, L.V. 1990. Introduction to plant disease epidemiology. John Wiley \& Sons: New York. 532 pp.

Cezar, M.A.; Krause-Sakate, R.; Pavan, M.A.; Costa, C.P. 2008 Evaluatin of resistance of Capsicum spp. genotypes to tobamovirus. Summa Phytopathologca, 35: 39-43.

Coelho Netto, R.A.; Pereira, B.G.; Noda, H; Boher, B. 2004.Bacterial wilt in Amazonas State, Brazil. Fitopatologia Brasileira, 29: 21-27 (in Portuguese, with abstract in English).

Egea, C.; Alcazar, M.D.; Candela, M.E. 1996. Capsidiol: its role in the resistance of Capsicum annuum to Phytophthora capsici. Physiology Plantarum, 98: 737-742.

Hayward, A.C. 1964. Characteristic of Pseudomonas solanacearum. Journal of Applied Bacteriology, 27: 265-277.
Hayward, A.C. 1991. Biology and epidemiology of bacterial wilt caused by Pseudomonas solanacearum. Annual Rewiew of Phytopathology, 29: 65-87.

Kelman, A. 1954. The relationship of patogenicity in Pseudomonas solanacearum to colony appearance on a tetrazolium medium. Phytopathology, 44: 693-695.

Király, Z.; Klement, Z. Solymosy, F.; Vörös, J. 1974. Methods in Plant Pathology. Akadémiai Kiado, Budapeste. 509 pp.

Kpêmoua, K.; Boher, B., Nicole, M.; Colatayud, P; Gêger, J.P. 1996. Cytochemistry of defense response in cassava infected by Xanthomonas campestris pv. manihots. Canadian Journal of Microbiology, 42: 1131-1143.

Lopes, C.A.; Boiteux, L.S. 2004. Biovar-specific and broad-spectrum sources of resistance to bacterial wilt (Ralstonia solanacearum) in Capsicum. Crop Breeding and Applied Biotechnology, 4: 350-355.

Nakaho, K.; Inoue, H.; Takayama, T.; Miyagawa, H. 2004. Distribution and multiplication of Ralstonia solanacearum in tomato with resistance derived from different origins. Journal of Genetics Plant Pathology, 70: 115-119.

Rahman, M.A.; Abdullah, H.; Vanhaecke, M. 1999. Histopathology of susceptible and resistant Capsicum annuum cultivars infected with Ralstonia solanacearum. Phytopathology, 147: 129-140.

Romeiro, R.S. 2001. Methods in plant bacteriology. Universidade Federal de Viçosa: Viçosa, Minas Gerais. 279 pp.(in Portuguese)

SAEG. 2007. System for Statistical Analyses. Fundação Arthur Bernardes:Viçosa, Minas Gerais.

Sands, D.C. Physiological criteria - Determinative Tests. In: Klement, Z.; Rudolph, K.; Sands, D.C. 1990. Methods in Phytobacteriology. Akadémiai Kiado, Budapeste. 568 pp.

Winstead, N.N.; Kelman, A. 1952. Inoculation techniques for evaluating resistance to Pseudomonas solanacearum. Phytopathology, 42: 628-634.

Rcebido em 23/06/2010

Aceito em 24/11/2010 